\title{
Vaginal Cancer cM0 TNM Finding v8
}

National Cancer Institute

\section{Source}

National Cancer Institute. Vaginal Cancer cMO TNM Finding v8. NCI Thesaurus. Code C139635.

Vaginal cancer without evidence of distant metastasis. (from AJCC 8th Ed.) 